\title{
Prognosis of Adamantinoma of Long Bones: A Long-Term Follow-Up Study
}

\author{
Khodamorad Jamshidi,, Sam Hajialilo Sami,, Farshad Abolghasemzadeh Ahangar,," and Nariman \\ Latifi $^{1}$ \\ ${ }^{1}$ Bone and Joint Reconstruction Research Center, Shafa Orthopedic Hospital, Iran University of Medical Sciences, Tehran, IR Iran \\ "Corresponding author: Farshad Abolghasemzadeh Ahangar, Bone and Joint Reconstruction Research Center, Shafa Orthopedic Hospital, Tehran, IR Iran. Tel: +98-9124454805; \\ +98-2133542022, E-mail: farshada1358@gmail.com
}

Received 2015 October 26; Revised 2016 January 13; Accepted 2016 April 15.

\begin{abstract}
Background: Adamantinoma of long tubular bones is a rare primary malignant bone tumor. According to the literature, different prognosis and recurrence rates have been reported.

Objectives: The purpose of this case series study was to evaluate the clinical behavior and prognostic features of adamantinoma of long bones.

Patients and Methods: In this study, 13 histologically proven cases of adamantinoma of long bones which were treated in our hospital during March 1977 to June 2015 were evaluated. The mean follow-up period was $72 \pm 44.4$ months. The male:female ratio was 10:3, aged between 13 and 63 years at the time of diagnosis (mean $=24.8 \pm 13.1$ years). There was a period between the onset of disease and definite diagnosis (mean: $17.5 \pm 14.7$ months). In two cases according to the imaging and clinical symptoms the lesion seemed to be osteofibrous dysplasia, but during the follow-up, the diagnosis was changed to adamantinoma when open biopsy and pathologic assessment were performed. In 10 cases the tumor was located in the tibial diaphysis, in two cases the location was the distal shaft of the femur, and in one case the location was proximal of the humerus. All the cases underwent wide resection and intercalary or osteoarticular allograft reconstruction as the main surgery after primary incisional biopsy.

Results: In eight cases, at least one local recurrence happened in an average 33.4-month period after the wide resection. In four of these patients rather than one local recurrence was occurred, but in one patient despite pulmonary metastasis the patient underwent pulmonary lobectomy and was alive at the end of the study. Allograft-related complications happened in five cases (two infections, one osteoarthritis of ankle, and two allograft fractures). For five patients ultimately recurrence and complication lead to amputation. Six patients died because of this disease, in all of which pulmonary metastasis occurred. The five-year survival rate in this study was $69 \%$.

Conclusions: Adamantinoma of long bone is a low-grade malignant tumor; however, wide resection tends to local recurrence and metastasis to the lung. Recurrence and metastasis can occur many years after surgery and there is a long disease-free period between the first wide resection and first recurrence and metastasis. This study underlined that despite the low-grade pathologic feature of this tumor, its behavior is like a high grade sarcoma and it may be better to perform sufficient wide resection at the first surgery with wide clear margin to reduce the rate of recurrence, but this approach needs to be assessed by prospective studies. According to clear wide margins for all of our cases, we guess this high interest for recurrence may be due to skip lesions of this tumor along the affected bone or even in the neighbor bones.
\end{abstract}

Keywords: Adamantinoma, Recurrence, Metastasis, Prognosis

\section{Background}

Adamantinoma of the long tubular bones is a rare primary malignant bone tumor with disputed histogenesis, first described and named by Fischer in 1913 (1). It accounts for $0.33 \%$ of all malignant bone tumors in the material of Dahlin and Unni (2) and $0.48 \%$ in that of Schajowicz et al. (3).

The number of cases in case series studies rarely exceeds 10 - 20 (4-7) with the exception of some multicenter studies $(8,9)$. In $85 \%-90 \%$ of cases, the tumor is local- ized to the tibia firstly on the middle third of the diaphysis, nonetheless it has also been described in the fibula, ulna, humerus, femur, and the short bones of the feet (8-12).

\section{Objectives}

This article reviews the clinical, radiological and prognostic features of this tumor and outcomes of treatments in some cases based on an average of $72 \pm 44.4$ months follow-up. 


\section{Patients and Methods}

The study protocol was approved by the ethics board of the institution. A total of 18 cases of adamantinoma of long bones were treated in our hospital during an 18-year period from March 1997 to June 2015. In five of these patients, primary wide resection was performed in other centers and then they were referred to our hospital because of local recurrence. These five patients were excluded from the study. Only those patients in whom wide resection surgery and other procedures were performed in our hospital were included in the study. For all of the cases, at first, diagnosis was confirmed by incisional biopsy; then, main surgery was performed and the bone defect was reconstructed by fresh frozen allograft. All 13 patients were treated by wide resection limb sparing surgery without any adjuvant therapy. Then, the bone defect was reconstructed by fresh frozen allograft (intercalary for nine cases and osteoarticular for four), which was fixed by $4.5 \mathrm{~mm}$ plates with at least three screws proximal and distal to the intercalary allograft and at least four screws beyond the osteoarticular allograft (Figure 1). Evaluation of the extension of tumor to the medullary canal and along the bone was performed by magnetic resonance imaging (MRI) and the length of the affected bone that needed resection was defined by coronal and sagittal MRI cuts (Figure 2).

Preoperative evaluation consisting of imaging and laboratory tests was conducted before surgery. Size of the tumor and its location were assessed by plain radiographs, MRI and technetium-99m bone scan. For all the cases lung was assessed by chest CT-scan for pulmonary metastasis, if present. After the main surgery, patients were followed by plain radiographs of the affected bone and chest every three months in the first three years and then every six months in the fourth and fifth years and then annually. If there was any sign of local recurrence or metastasis, further evaluation by intravenous (IV) contrast-enhanced MRI and chest CT-scan was performed and when the recurrence of disease was confirmed, radical resection of the tumor was performed by amputation or secondary limb salvage surgery.

\section{Results}

Clinical data of 13 patients are summarized in Table 1. Ten patients were male and three were female (male:female ratio: 10:3). Patients' ages ranged from 13 to 63 years (mean age $=24.8 \pm 13.1$ years). In 10 cases the tumor was located in the tibia, in two it was found in the distal of femoral shaft, and in one case it was located in the proximal shaft of the humerus. The tibial tumors in four cases was located in distal third of diaphysis, in three cases
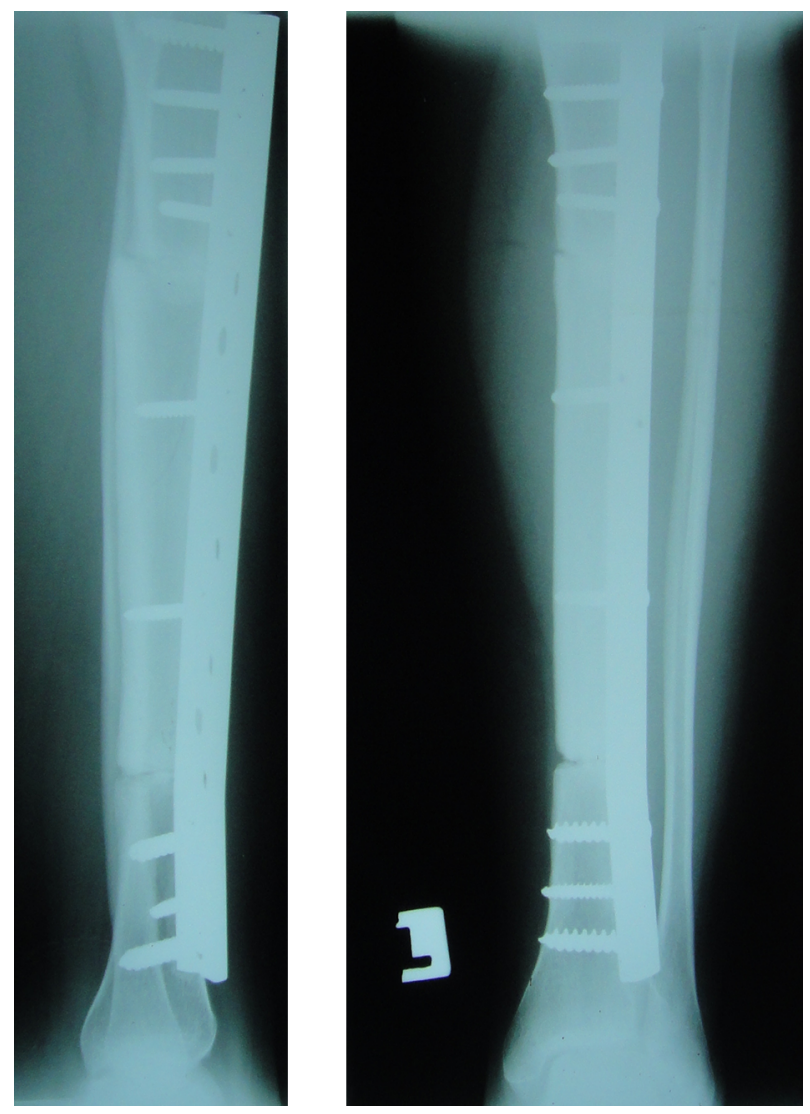

Figure 1. Intercalary Allograft Fixed by Plate and Screws

it was in the proximal third and in three cases the location was the middle third. There was a period between the onset of symptoms and the definite diagnosis. Duration of the symptom-positive period before diagnosis and treatment was form two months to four years (mean $=17.5 \pm$ 14.7 months). All the patients complained of palpable mass and in 11 patients the tumor was painful. One of the cases had pathologic fracture at the time of diagnosis.

For both painless cases, at first, according to the imaging results and clinical symptoms, the lesion seemed to be osteofibrous dysplasia; then through follow-up, progression in the size of the tumor needed biopsy, and finally adamantinoma was diagnosed.

In all the patients, the radiographic feature of the tumor was a multicystic, lytic, eccentric expansile lesion in the diaphysis of the tibia or femur, which was localized in the cortex and then affected the medullary canal (Figure 3 ). All lytic cysts were surrounded by sclerotic bone which was best seen by CT-scan (Figure 4). A union between allograft and host bone was achieved in 12 cases in the first year (for one patient after 18 months). For four patients, an autoge- 
Table 1. Data of Demographics, Surgical Procedures and Results

\begin{tabular}{|c|c|c|c|c|c|c|c|c|c|c|c|}
\hline Case & Age, $y$ & Gender $(M / F)$ & $\begin{array}{c}\text { Time to } \\
\text { Diagnosis, mo }\end{array}$ & Type of Surgery & Location & $\begin{array}{c}\text { Time to } \\
\text { Recurrence, mo }\end{array}$ & $\begin{array}{l}\text { Location of } \\
\text { Metastasis }\end{array}$ & $\begin{array}{c}\text { Time to } \\
\text { Metastasis }\end{array}$ & Follow-Up & Dead or Alive & Survival \\
\hline 1 & 21 & $\mathrm{~F}$ & 12 & $W R+I C A$ & Rt. distal femur & 20 & Lung & 34 & 36 & Dead & 48 \\
\hline 2 & 34 & M & 12 & WR + ICA & Lt. distal femur & 26 & Lung & 17 & 36 & Dead & 48 \\
\hline 3 & 63 & M & 24 & $\mathrm{WR}+\mathrm{OAA}$ & Lt. distal tibia & . & . & . & 200 & Alive & 224 \\
\hline 4 & 16 & $\mathrm{~F}$ & 24 & $W R+I C A$ & Rt. distal tibia & 8 & Lung & 40 & 50 & Dead & 74 \\
\hline 5 & 15 & M & 8 & $\mathrm{WR}+\mathrm{OAA}$ & Lt. proximal tibia & 9 & Lung & 42 & 48 & Dead & 56 \\
\hline 6 & 18 & M & 4 & WR + ICA & Rt. distal tibia & 12 & $\begin{array}{l}\text { Lung + Lymph } \\
\text { node }\end{array}$ & 32 & 48 & Dead & 52 \\
\hline 7 & 15 & M & 48 & $W R+I C A$ & Rt. distal tibia & 90 & . & 96 & 102 & Dead & 150 \\
\hline 8 & 22 & M & 36 & $W R+I C A$ & Lt middle tibia & 74 & . & . & 91 & Alive & 127 \\
\hline 9 & 23 & M & 6 & $\mathrm{WR}+\mathrm{OAA}$ & Lt. proximal tibia & . & - & . & 91 & Alive & 97 \\
\hline 10 & 24 & M & 6 & $\mathrm{WR}+\mathrm{OAA}$ & Lt. proximal tibia & - & Lung & 63 & 80 & Alive & 86 \\
\hline 11 & 27 & M & 36 & $\mathrm{WR}+\mathrm{ICA}$ & Rt. Humerus & . & - & - & 45 & Alive & 81 \\
\hline 12 & 32 & M & 9 & $W R+I C A$ & Rt. middle tibia & 28 & - & . & 51 & Alive & 60 \\
\hline 13 & 13 & $\mathrm{~F}$ & 2 & $W R+I C A$ & Lt. middle tibia & . & . & . & 58 & Alive & 60 \\
\hline
\end{tabular}

Abbreviations: ICA, intercalary allograft; OAA, osteoarticular allograft; WR, wide resection.

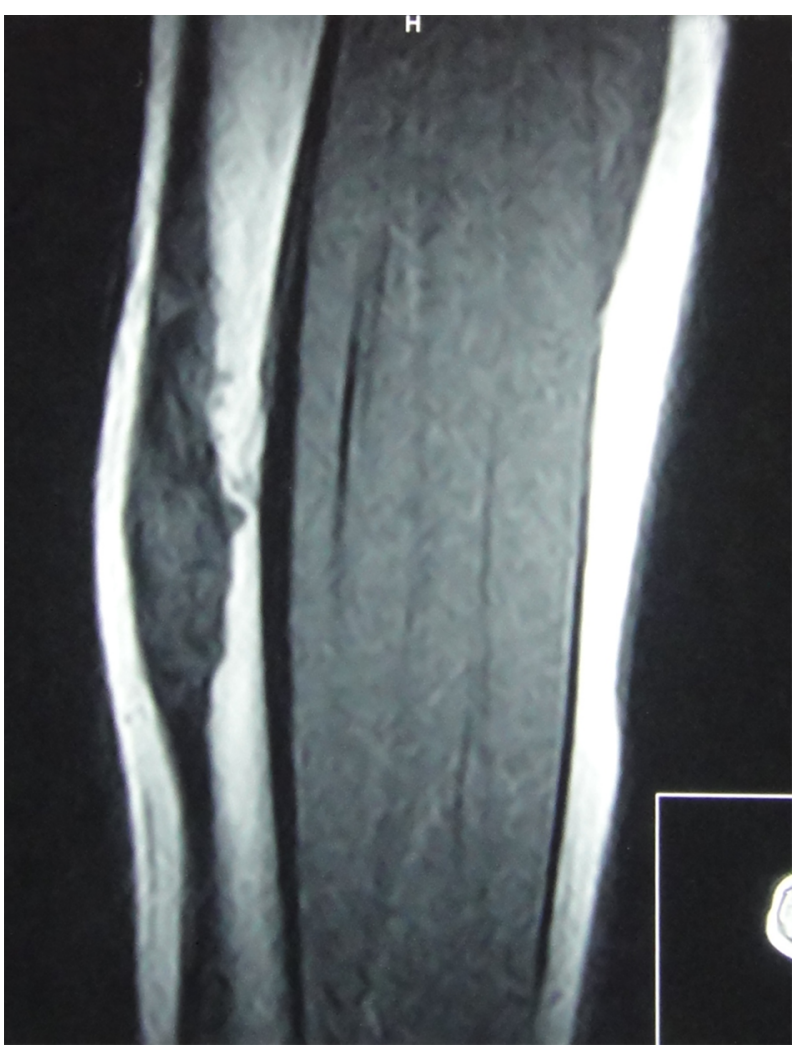

Figure 2. Definition of the Extension of Tumor in the Sagittal Cut of Magnetic Resonance Imaging

nous bone graft from iliac crest was needed because of delayed union. After the main surgery, patients were under close follow-up. In eight cases local recurrence occurred and the time from the surgery to the first recurrence was 8 to 90 months (mean $=33.4 \pm 29.2$ months). In seven cases with local recurrence, pulmonary metastasis finally occurred and ultimately six of these patients died from the disease, but one of the patients who had pulmonary metastasis underwent pulmonary lobectomy and was still alive approximately three years post-metastasectomy. The period from the surgery to the diagnosis of pulmonary metastasis was 17 to 96 months (mean $=46.3 \pm 24$ months). In one case, inguinal lymph node metastasis occurred simultaneously with lung metastasis. The follow-up period for our patients was 36 to 200 months (mean $=72 \pm 44.4$ months).

Maximum survival was 224 months, in which the patients is still alive and disease-free. Five-year survival from the onset of symptoms was $69 \%$ ( 9 of 13 patients) and the final survival of the patients at the end of our study was $54 \%$ (7 of 13 patients).

\section{Discussion}

Several authors have pointed to the close relationship between conventional adamantinoma, the so-called differentiated adamantinoma (osteofibrous dysplasia-like adamantinoma) and osteofibrous dysplasia, which can cause serious differential diagnostic problems because of similar radiological and histological appearance and typical location in the tibia (12-16).

The clinical relevance is different behaviors of these entities: while osteofibrous dysplasia is a benign process and active surgical treatment is disputed, osteofibrous dysplasia-like adamantinoma can regress spontaneously, 

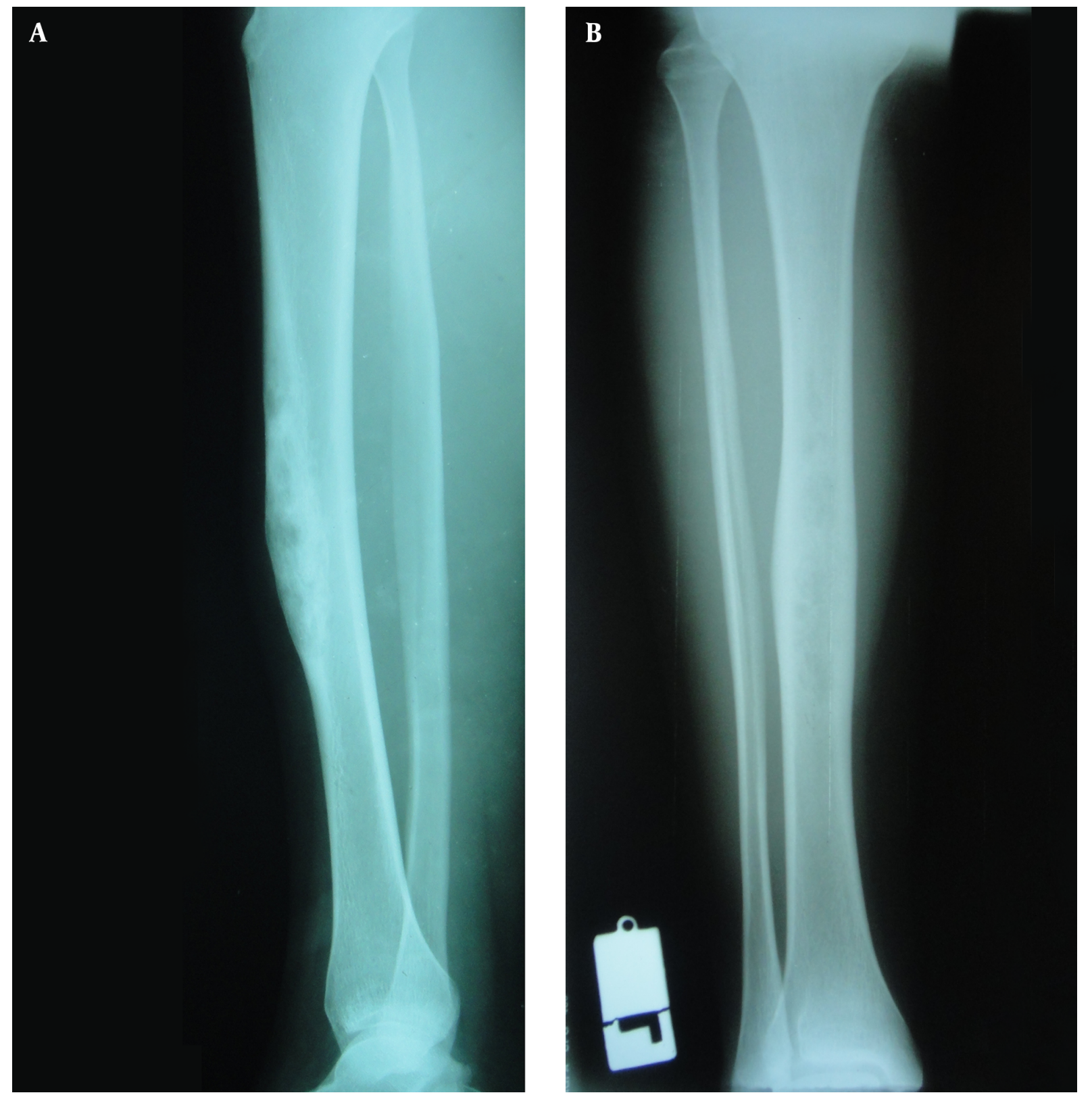

Figure 3. Anteroposterior and Lateral Radiography of Left Leg of a 24-Year-Old Patient With Adamantinoma of Tibia

but it is also regarded as the precursor of a conventional adamantinoma $(14,17)$.

Most of the demographic data of our patients are in accordance with the data publications reporting on higher numbers of cases $(8,18,19)$. In our cases, tumor appeared $77 \%$ in males and $92 \%$ in young adults under 35 years of age. Tumor was localized mostly in tibia; however, in our study, distal third was the most frequent site.

According to the literary data $(8,10,20)$, symptoms in- clude slight pain, swelling, and deformation of the bone during a long period. According to our results, this feature was also seen in our cases with 17.5 months mean period from the onset of symptoms to the diagnosis of disease. Szendroi et al. (19) reported 42 months delay in 11 patients and Qureshi et al. (8) also reported 62 months delay in 60 patients from the onset of symptoms to the definite diagnosis. The prevalence of pathologic fracture as the first symptom can reach to $20 \%(8,21)$. In our cases, one 


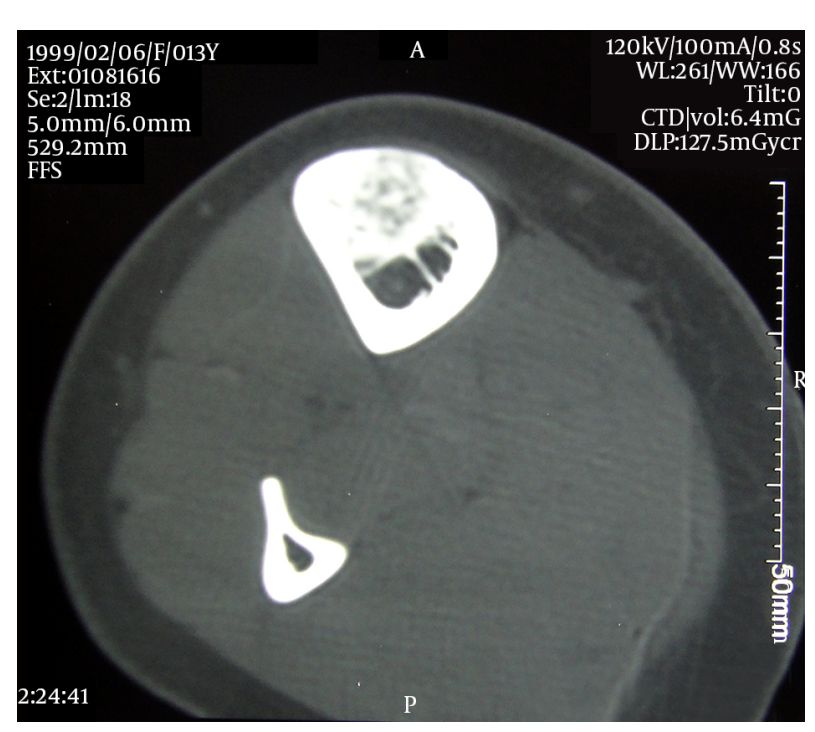

Figure 4. Axial Cut of CT Scan of Adamantinoma of Tibia

patient was referred with pathologic fracture as the early symptom before diagnosis (7.7\%).

The location and radiological appearance of the tumor is characteristic in most cases. Adamantinoma appears as an eccentric destructive lesion, usually located in the anterior cortex of the diaphysis of tibia. Cortex slightly expands becomes deformed. Tumor has a cystic, multilocated feature with a sclerotic rim. The cortical bone is thinned and ultimately destroyed without any periosteal reaction (22).

CT-scan is useful for evaluation of the cortical destruction and it demonstrates the sclerotic bony septa separating the cysts (19). The different tumor foci appear with high signal intensity on either T2 weightened images or with T1 weightened contrast enhanced image by MRI. Neither CT nor MRI is able to differentiate between the differentiated and conventional forms of adamantinoma (23). In the minority of the cases, adamantinoma appears as an intramedullary solitary lobulated focus resembling on bone metastasis (12).

Curettage and bone grafting are not recommended because of the frequent recurrences $(9,10)$. In the past, several authors $(5,24)$ advised amputation, emphasizing the multicentric nature of adamantinoma. Extensive resection in case of primary tumor and amputation upon recurrence have been suggested by Gebhardt et al. (25) and others $(9,10)$.

According to our experience, we guess sufficient wide resection should be performed primarily without obsession in salvage of the function of the limb, and even primary amputation in massive lesion may lead to better prognosis according to the high rate of local recurrence and metastasis of course; this theory should be proven by prospective studies. Recurrence of the tumor in adjacent bone in two of our cases improves the theory of multicentric behavior skip lesions; so, a primary massive wide resection is needed. Reconstruction techniques after En bloc resection of the tumor include the use of allograft, vascularized and non-vascularized autografts, distraction osteogenesis and segmental tumor endoprosthesis (12). In our cases, reconstruction with intercalary or osteoarticular allograft had good results and union between allograft and host bone occurred in almost all cases during the first postoperation year. We think prevention of donor site morbidity can be a main benefit of using allograft. However, the rates of reconstruction-related complications are still unacceptably high in literature. Ortiz-cruz et al. (26) reported infection, fracture and nonunion with rates as high as $12 \%, 17 \%, 29 \%$ out of 104 patients, respectively. In our cases, rate of infection, fracture and secondary joint osteoarthritis were $15.4 \%$ (two cases), $15.4 \%$ (two cases), and $7.7 \%$ (one case), respectively. We did not have any problem with union; however, in four cases, secondary autologous iliac crest bone graft was needed for delayed union.

The evaluation of the outcome of disease is difficult according to the mysterious behavior and slow progression of the tumor. In literature, $6 \%-18 \%$ mortality rates have been reported and metastasis to the lung or lymph nodes were as high as $12 \%-29 \%(8-10,12)$. Negative prognostic factors for recurrence are young age, male gender, history of pain, and aggressive growth $(9,10)$.

The recurrence rate is reported in the literature as high as $30-35 \%(7,18)$. Insufficient intralesional curettage with bone grafting leads to local recurrence in nearly all cases $(8-10,12,19,27,28)$. Recurrence of adamantinoma can occur even after 10 - 20 years following surgery (19). According to our study, we had $62 \%$ local recurrence and $46 \%$ mortality. The rate of lung and lymph node metastasis were 54\% and $8 \%$, respectively. These results showed higher mortality and local recurrence and metastasis rates in our patients compared with previous studies.

Our study was retrospective and this was a limitation; so, it is better to reassess these results by future prospective studies. Our hospital is a referral center for musculoskeletal tumors and fortunately all preoperative work-up results and follow-up reports for these patients were systemically saved and are available. All main surgeries were performed by two well-practiced musculoskeletal tumor surgeons through standard and correct principles. The number of patients in our study was good in comparison with similar studies $(8,18,19)$. However, the five-year survival rate of our cases was $69 \%$ (nine cases), which according to the final survival rate (54\%, only seven cases were alive at the end of the study) shows that very late recur- 
rence and metastasis can occur and long-term follow up is necessary for these patients.

\section{Footnote}

Authors' Contribution: Khodamorad Jamshidi: study design; Sam Hajialilo Sami, Farshad Abolghasemzadeh Ahangar, Nariman Latifi: data acquisition; Khodamorad Jamshidi, Sam Hajialilo Sami, Farshad Abolghasemzadeh Ahangar, Nariman Latifi: manuscript preparation and revision.

\section{References}

1. Fischer B. Ube ein primares Adamantinoma der tibia. Virchows Arch. 1913;12:422-41.

2. Dahlin DC, Unni KK. Bone tumors: general aspects and data on 8,542 cases. Charles C. Thomas Publisher; 1986.

3. Schajowicz F, Cabrini RL, Gimenez I. Microspectrophotometric quantitation of DNA in bone tumors with giant cells (osteoclastoma, osteosarcoma and chondroblastoma). Clin Orthop Relat Res. 1981(156):917. [PubMed: 6939515].

4. Campanacci M, Bertoni F, Bacchini P. Bone and Soft Tissue Tumors. Springer; 1990. pp. 629-38.Adamantinoma of the long bones.

5. Czerniak B, Rojas-Corona RR, Dorfman HD. Morphologic diversity of long bone adamantinoma. The concept of differentiated (regressing) adamantinoma and its relationship to osteofibrous dysplasia. Cancer. 1989;64(11):2319-34. [PubMed: 2804923].

6. Huvos AG, Marcove RC. Adamantinoma of long bones. A clinicopathological study of fourteen cases with vascular origin suggested. J Bone Joint Surg Am. 1975;57(2):148-54. [PubMed: 1112840].

7. Hazelbag HM, Taminiau AH, Fleuren GJ, Hogendoorn PC. Adamantinoma of the long bones. A clinicopathological study of thirty-two patients with emphasis on histological subtype, precursor lesion, and biological behavior. J Bone Joint Surg Am. 1994;76(10):1482-99. [PubMed: 7929496].

8. Qureshi AA, Shott S, Mallin BA, Gitelis S. Current trends in the management of adamantinoma of long bones. An international study. J Bone Joint Surg Am. 2000;82-A(8):1122-31. [PubMed: 10954102].

9. Keeney GL, Unni KK, Beabout JW, Pritchard DJ. Adamantinoma of long bones. A clinicopathologic study of 85 cases. Cancer. 1989;64(3):730-7. [PubMed: 2743266].

10. Moon NF, Mori H. Adamantinoma of the appendicular skeletonupdated. Clin Orthop Relat Res. 1986(204):215-37. [PubMed: 3514033].

11. Ulmar B, Delling G, Werner M, Huch K, Reichel H. Classical and atypical location of adamantinomas-presentation of two cases. Onkologie. 2006;29(6):276-8. [PubMed: 16783903].

12. Papagelopoulos PJ, Mavrogenis AF, Galanis EC, Savvidou OD, Inwards CY, Sim FH. Clinicopathological features, diagnosis, and treatment of adamantinoma of the long bones. Orthopedics. 2007;30(3):211-5. [PubMed: 17375547] quiz 216-7.
13. Hazelbag HM, Wessels JW, Mollevangers P, van den Berg E, Molenaar WM, Hogendoorn PC. Cytogenetic analysis of adamantinoma of long bones: further indications for a common histogenesis with osteofibrous dysplasia. Cancer Genet Cytogenet. 1997;97(1):5-11. [PubMed: 9242211].

14. Kahn LB. Adamantinoma, osteofibrous dysplasia and differentiated adamantinoma. Skeletal Radiol. 2003;32(5):245-58. doi: 10.1007/s00256-003-0624-2. [PubMed: 12679847].

15. Kuruvilla G, Steiner GC. Osteofibrous dysplasia-like adamantinoma of bone: a report of five cases with immunohistochemical and ultrastructural studies. Hum Pathol. 1998;29(8):809-14. [PubMed: 9712421].

16. Maki M, Athanasou N. Osteofibrous dysplasia and adamantinoma: correlation of proto-oncogene product and matrix protein expression. Hum Pathol. 2004;35(1):69-74. [PubMed: 14745727].

17. Hatori M, Watanabe M, Hosaka M, Sasano H, Narita M, Kokubun S. A classic adamantinoma arising from osteofibrous dysplasia-like adamantinoma in the lower leg: a case report and review of the literature. Tohoku J Exp Med. 2006;209(1):53-9. [PubMed:16636523]

18. Jundt G, Remberger K, Roessner A, Schulz A, Bohndorf K. Adamantinoma of long bones. A histopathological and immunohistochemical study of 23 cases. Pathol Res Pract. 1995;191(2):112-20. doi: 10.1016/S0344-0338(11)80560-1. [PubMed: 7567680]

19. Szendroi M, Antal I, Arato G. Adamantinoma of long bones: a longterm follow-up study of 11 cases. Pathol Oncol Res. 2009;15(2):209-16. doi: 10.1007/s12253-008-9125-x. [PubMed: 19048403].

20. Szendroi M, Renyi-Vamos A, Marschalko P. Csoves Csontok adamantinomainak viselkedese hosszu tavu utankovetes alapjan. Magy Traum Orthop. 1994;37:37-44.

21. Bely M, Gal D. [A case of adamantinoma localized to the tibia (author's transl)]. Magy Traumatol Orthop Helyreallito Seb. 1982;25(1):75-9. [PubMed: 6121955].

22. Bohndorf K, Nidecker A, Mathias K, Zidkova H, Kaufmann H, Jundt G. [The radiological findings in adamantinoma of the long tubular bones]. Rofo. 1992;157(3):239-44. doi: 10.1055/s-2008-1033006. [PubMed: 1391818]

23. Van der Woude HJ, Hazelbag HM, Bloem JL, Taminiau AH, Hogendoorn PC. MRI of adamantinoma of long bones in correlation with histopathology. AJR Am J Roentgenol. 2004;183(6):1737-44. doi: 10.2214/ajr.183.6.01831737. [PubMed: 15547221].

24. Baker PL, Dockerty MB, Coventry MB. Adamantinoma (so-called) of the long bones; review of the literature and report of three new cases. J Bone Joint Surg Am. 1954;36-A(4):704-20. [PubMed:13174600].

25. Gebhardt MC, Lord FC, Rosenberg AE, Mankin HJ. The treatment of adamantinoma of the tibia by wide resection and allograft bone transplantation. J Bone Joint Surg Am. 1987;69(8):1177-88. [PubMed: 3312206].

26. Ortiz-Cruz E, Gebhardt MC, Jennings LC, Springfield DS, Mankin HJ. The results of transplantation of intercalary allografts after resection of tumors. A long-term follow-up study. J Bone Joint Surg Am. 1997;79(1):97-106. [PubMed: 9010190].

27. Rock MG, Beabout JW, Unni KK, Sim FH. Adamantinoma. Orthopedics. 1983;6(4):472-7. doi: 10.3928/0147-7447-19830401-09. [PubMed 24823160].

28. Mori H, Yamamoto S, Hiramatsu K, Miura T, Moon NF. Adamantinoma of the Tibia: Ultrastructural and Immunohistochemic Study with Reference to Histogenesis. Clin Orthopaed Related Res. 1984;190:299-310. 